\title{
Prevalence of dental fluorosis and its determinants among primary school children in Koppal district, Karnataka: A cross-sectional study
}

\author{
Smita M Nimbannavar ${ }^{1}$, Yuvaraj B $\mathbf{Y}^{2 *}$, Vijaykumar Mane ${ }^{3}$, Anilkumar $\mathbf{L}^{4}$, Sharankumar Holyachi ${ }^{5}$, Chetana $\mathrm{K} \mathrm{V}^{6}$ \\ 1,3-6 Assistant Professor, ${ }^{2}$ Professor and Head, Dept. of Community Medicine, Koppal Institute of Medical Sciences, Koppal, Karnataka, \\ India
}

*Corresponding Author: Yuvaraj B Y

Email: dryuvraj@gmail.com

\begin{abstract}
Introduction: Fluorosis is an important public health problem across the globe. Intake of Fluoride higher than the optimum level is the main reason for occurrence of Dental and Skeletal Fluorosis. School going children are most commonly affected by Dental Fluorosis.

Objectives: 1): To estimate the prevalence of Dental fluorosis among primary school children aged 6-12 years in rural areas of Koppal district. 2): To determine various factors associated with Dental fluorosis in children.

Material and Methods: A community based cross-sectional study was conducted in rural areas of Koppal district. A total of 3047 school children in the age group of 6-12 years were included in the study by cluster sampling technique. Dental Fluorosis was identified and graded using Modified Dean's Flurosis Index and data were collected using a pretested and semi-structured questionnaire. Statistical analysis was done using WHO Epi info software version 3.5.4.

Results: The Prevalence of Dental Fluorosis among school children in Koppal district was 2279 (74.8\%) as per Modified Dean's Fluorosis Index and it was found to be significantly associated with type of diet and source of drinking water among them.

Conclusion: The present study concludes that the prevalence of Dental Fluorosis was high in Koppal district and was associated with age, was more in children on mixed diet and drinking ground water.
\end{abstract}

Keywords: Dental Fluorosis, Determinants, Modified Dean's index, School children.

\section{Introduction}

Fluorine is the most abundant element in nature. It is required by the body for mineralization of bones and formation of Dental enamel especially during first 7 years of life. Ground water, Soil and Foods items like sea fish, cheese and tea are the main sources of Fluroine and Fluorine ingested through these sources gets stored in bones and teeth. The upper limit of Fluoride in drinking water is $1.5 \mathrm{mg} / \mathrm{L}$ as recommended by World Health Organisation (WHO), but in temperate countries where the water intake is more, excess Fluroide consumption may pose a threat. In these areas the maximum permissible limit for Fluoride should be less. The Bureau of Indian standards has laid down the maximum permissible limit of $1.0 \mathrm{mg} / \mathrm{L} .^{1-4}$

Fluorine is a double edged sword. When consumed within limits, it prevents occurrence of Dental caries, but when consumed in excess leads to mottling of Dental enamel which has been reported at levels above $1.5 \mathrm{mg} / \mathrm{L}$. The teeth will become hard and brittle if the consumption of fluorine at excess levels continues for prolonged periods. In the initial stages, the tooth becomes yellow and later on changes to brown or black depending on the severity and this discoloration either appears as spots or streaks. H. Trendley Dean in 1934 first published Dean's Fluorosis index for classifying and recording Dental Fluorosis. Later it was revised in 1942, and modified by many researchers in particular by Horowitz and others in 1984..$^{2,5-8}$

Karnataka, a southern state in India, is endemic for Dental Fluorosis. Around 20 districts in Karnataka have fluoride content in water more than $1.5 \mathrm{mg} / \mathrm{L}$ and Koppal is one among them. ${ }^{9,10}$ The fluoride content in the water ranges from 1.51 to $16.6 \mathrm{mg} / \mathrm{L}$ in different parts of Koppal district and school going children are most commonly affected by Dental Fluorosis. Lack of data on prevalence, severity and determinants of Dental Fluorosis in Koppal district prompted us to undertake the present study with following objectives.

\section{Objectives of the Study}

1. To estimate the prevalence of Dental fluorosis among primary school children aged 6-12 years in rural areas of Koppal district.

2. To determine various factors associated with Dental fluorosis in children.

\section{Materials and Methods}

Design of study

Community based cross sectional study.

\section{Period of study \\ April 2018 - July 2018.}

\section{Study setting}

Koppal district, Karnataka

\section{Study population}

All the primary school children aged 6-12 years in rural areas of Koppal district, Karnataka.

\section{Sample size}

Minimum sample size calculated was 2166 with absolute precision of $3 \%$ and significance level of 0.05 and design effect of 2, taking $42 \%$ prevalence of Dental fluorosis in Karnataka $^{11}$ as per recent estimates. We included 3047 
school children aged between 6 years to 12 years in the present study.

\section{Sampling technique}

Cluster sampling technique was used for sample selection. All the villages in Koppal district were considered as Individual clusters and 30 such clusters/ villages were selected by Population Proportional to size sampling. In each of the selected cluster/ village, one school was selected by simple random sampling and in each selected school, a total of 105 children (15 each from class 1 to 7 ) were selected and included as study participants by systematic sampling technique. If the required number of children were unavailable at that particular school, other schools in the vicinity were visited till a sample of 105 children was reached for that particular cluster.

\section{Data collection}

Dental Fluorosis among study participants was detected and graded using "Modified Dean's Fluorosis Index" in addition to collection of relevant data using pretested and semi structured questionnaire, after obtaining consent from Headmaster of school and accent from individual children.

\section{Statistical analysis}

Was done using WHO Epi info software version 3.5.4.

\section{Results}

Out of the 3150 questionnaires collected from 30 clusters in the present study, some were discarded owing to incomplete, inaccurate and inconsistent entries, thereby leaving 3047 questionnaires for final analysis.

Fig 1: Reveals prevalence of various grades of Dental fluorosis in Koppal district. The prevalence of Dental fluorosis among school children in the present study was $2279(74.8 \%)$ and the highest prevalence was of very mild grade i.e. 1002 (32.8\%) followed by severe grade as seen in the figure.

Table 1: Demonstrates age wise prevalence of Dental Fluorosis among school children. The present study found gradual increase in the prevalence of Dental Fluorosis with increase in age group among school children and the association was found to be statistically significant ( $\mathrm{P}<$ $0.05)$.

Table 2: Distribution of Dental Fluorosis among school children according to some important variables. As seen in the table, the prevalence of Dental Fluorosis was almost similar among both male and female children and the study found no significant association between gender and prevalence of Fluorosis. However, the prevalence of Dental Fluorosis was significantly $(\mathrm{P}<0.05)$ more in school children consuming Mixed diet i.e. 1771 (76.30\%) compared to their vegetarian counterparts and also the prevalence was significantly $(\mathrm{P}<0.05)$ more among children drinking ground water i.e. 1571 (76.48\%) compared to those who consumed surface water. However, the prevalence of Dental Fluorosis had significant association neither with frequency of brushing teeth in a day nor with religion of the child in the present study.

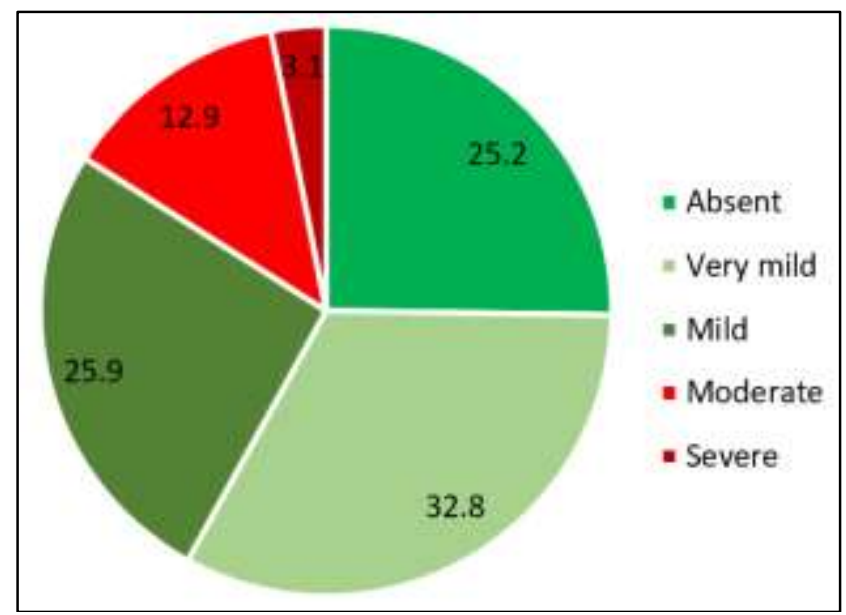

Fig. 1: Prevalence of various grades of dental fluorosis among school children in Koppal district as per "Modified Dean's Fluorosis Index"

Table 1: Prevalence of Dental Fluorosis among school children in Koppal district according to their age

\begin{tabular}{|c|c|c|c|}
\hline \multirow{2}{*}{ Age (Years) } & Number of Children & \multicolumn{2}{|c|}{ Status of Dental Fluorosis n (\%) } \\
\cline { 3 - 4 } & $\mathbf{N}$ & Present & Absent \\
\hline 6 & 369 & $181(49.05)$ & $188(50.95)$ \\
\hline 7 & 441 & $283(64.17)$ & $158(35.83)$ \\
\hline 8 & 432 & $346(80.09)$ & $86(19.91)$ \\
\hline 9 & 441 & $352(79.81)$ & $89(20.19)$ \\
\hline 10 & 448 & $378(84.37)$ & $70(15.63)$ \\
\hline 11 & 466 & $383(82.18)$ & $83(17.82)$ \\
\hline 12 & 450 & $356(79.11)$ & $94(20.89)$ \\
\hline Total & 3047 & $2279(74.79)$ & $768(25.21)$ \\
\hline & \multicolumn{2}{|c|}{$\chi^{2}=208.219, \mathrm{P}=0.000$} \\
\hline
\end{tabular}


Table 2: Prevalence of Dental Fluorosis among school children in Koppal district according to other variables

\begin{tabular}{|c|c|c|c|c|c|}
\hline Variable & Classificatio & Number of & \multicolumn{2}{|c|}{ Status of Dental Fluorosis n (\%) } & \\
\cline { 3 - 5 } & $\mathbf{n}$ & Children N & Present & Absent & \\
\hline \multirow{2}{*}{ Gender } & Male & 1494 & $1136(76.03)$ & $358(23.97)$ & \multirow{2}{*}{$\chi^{2}=2.400$} \\
& Female & 1553 & $1143(73.59)$ & $410(26.41)$ & $\mathrm{P}=0.121$ \\
\hline \multirow{2}{*}{ Diet } & Vegetarian & 726 & $508(69.97)$ & $218(30.03)$ & $\chi^{2}=11.757$ \\
& Mixed & 2321 & $1771(76.30)$ & $550(23.70)$ & $\mathrm{P}=0.000$ \\
\hline \multirow{2}{*}{$\begin{array}{c}\text { Source of drinking } \\
\text { water }\end{array}$} & Ground & 2054 & $1571(76.48)$ & $483(23.52)$ & $\chi^{2}=9.548$ \\
\cline { 2 - 5 } $\begin{array}{c}\text { Frequency of } \\
\text { brushing }\end{array}$ & Surface & 993 & $708(71.29)$ & $285(29.71)$ & $\mathrm{P}=0.002$ \\
\cline { 2 - 5 } & 1 & 2794 & $2080(74.44)$ & $714(25.56)$ & $\chi^{2}=3.864$ \\
\cline { 2 - 4 } & 2 & 246 & $197(80.08)$ & $49(19.92)$ & $\mathrm{P}=0.144$ \\
\cline { 2 - 4 } Religion & 3 & 7 & $5(71.42)$ & $2(28.58)$ & \\
\cline { 2 - 4 } & Hindu & 2912 & $2185(75.03)$ & $727(24.97)$ & $\chi^{2}=2.266$ \\
\cline { 2 - 4 } & Muslim & 115 & $81(70.43)$ & $34(29.57)$ & \\
\cline { 2 - 4 } & Others & 20 & $13(65.00)$ & $7(35.00)$ & \\
\hline
\end{tabular}

\section{Discussion}

Koppal district is one of the most backward districts in Hyderabad Karnataka region in Karnataka state as per Article $371 \mathrm{~J}$. The present study was first of its kind involving such a large sample size of primary school children aged 6-12 in rural areas and the sample was selected by cluster sampling technique. Apart from estimating the prevalence of Dental Fluorosis among school children, the present study also made an attempt to identify some of its determinants for effective planning of interventions.

The prevalence of Dental fluorosis among school children in rural areas of Koppal district was 2279 (74.8\%), which is very high compared to other studies done both within and outside India during different time periods ${ }^{11,13-18}$ and majority of them have used the same Dean's fluorosis to detect Dental Fluorosis. However, a couple of studies done in Rajasthan ${ }^{19}$ and Karnataka ${ }^{20}$ have found prevalence of Dental fluorosis in their studies comparable to the present study. A study by Sebastian ST et.al. ${ }^{11}$ in Mysore district of Karnataka and a study by Chaudhary $\mathrm{M}$ et.al. ${ }^{15}$ in Greater Noida of Uttar Pradesh have found Very Mild form of Dental Fluorosis to be the most prevalent form similar to the findings of present study. On the contrary, a number of studies ${ }^{13,14,18,19}$ have found mild form to be the most prevalent form among their study participants. This difference could be due to differences in study settings, differences in profile of study subjects, differences in Indices used to detect Fluorosis, Subjective errors in grading of Dental Fluorosis etc.

The present study found a significant association between the prevalence of Dental Fluorosis and the age group of study participants, in line with the findings of studies by Reddy KS et.al. ${ }^{16}$ in Telangana, Chauhan D et.al. ${ }^{18}$ in Himachal Pradesh and Sarvaiyu BU et.al. ${ }^{19}$ in Rajasthan. However, there was no association between prevalence and Gender in the present study, contrary to the findings of study by Khan SQ et.al. ${ }^{13}$ where the prevalence was significantly more in male children and study by Patel HR et.al. ${ }^{17}$ where the prevalence was significantly more among female children. Further, the prevalence of Dental
Fluorosis was significantly more in school children who consumed mixed diet and also more among children who drank ground water in the present study. A study by Monica Chaudhary et al. ${ }^{15}$ in UP has found higher prevalence of Dental fluorosis among those whose source of drinking water was Hand pump compared to Well and Tap. However, another study from Karnataka ${ }^{20}$ which evaluated the role of source of drinking water has found no such association with Dental Fluorosis. But we could not find any studies which have tested the association between type of diet and Dental fluorosis unlike the present study.

\section{Conclusion}

The prevalence of Dental Fluorosis among school children in rural areas of Koppal district is very high with three in every four children being affected with various grades and it was found to be significantly associated with age, diet and source of drinking water. It is recommended to reduce the fluoride content in drinking water by either making alternate water sources available or by setting up of Community defluoridation plants.

\section{Acknowledgement}

We acknowledge all the Medical social workers, Group D workers as well as undergraduate students posted in the department of Community Medicine for their active participation in field work for survey.

\section{Source of Funding}

None.

\section{Conflict of Interest}

None.

\section{References}

1. Park K. Park's Text book of Preventive and Social Medicine. $25^{\text {th }}$ ed. Jabalpur: M/s Banarasisdas Bhanot Publishers.2019:682.

2. Ateria G, Khadder VK, Phadnis S. Overview on Fluoride concentration in Drinking Water. Int J Theor Appl Sci. 2015;7(2):21-4. 
3. "Guidelines for Drinking water Quality". Available at: https://www.who.int/water_sanitation_health/dwq/GDWQ200 4web.pdf Accessed on 25/04/2019

4. "Prevention and Control of Fluorosis in India" Available at: https://www.ircwash.org/sites/default/files/245.4-11868.pdf Accessed on 25/04/2019

5. Den Besten P, Li W. Chronic Fluoride Toxicity: Dental Fluorosis. Monogr Oral Sci. 2011;22(81):81-96.

6. Ekstrand J, Fejerskov O, Silverstone L. Fluoride in dentistry. JAMA. 1991;266(22):2-8.

7. Mohamed AR, Thomson WM, Mackay TD. An epidemilogical comparison of Dean's index and the Developmental Defects of Enamel (DDE) index. J Public Health Dent. 2010;70(4):344-7.

8. Horowitz HS, Driscoll WS, Meyers RJ, SB Heifetz SB, Kingman A. A new method for assessing the prevalence of dental fluorosis: The tooth surface index of fluorosis. $J \mathrm{Am}$ Dent Assoc. 1984;109(1):37-41.

9. "Central Ground Water Board" Available at URL http://cgwb.gov.in/gw_profiles/st_karnataka.html Accessed on 25/04/2019

10. "Ground Water Year Book of Karnataka State 2015-16" Available at URL http://cgwb.gov.in/Regions/GW-yearBooks/GWYB-2015-16/GWYB\%20SWR\%202015-16.pdf Accessed on 25/04/19

11. Sebastian ST, Soman RR, Sunitha S. Prevalence of dental fluorosis among primary school children in association with different water fluoride levels in Mysore district, Karnataka. Indian J Dent Res. 2016;27:151-4.

12. "Deans Index" Available at URL http://www.fluorosisindex.com/deansindex Accessed on 25/04/19

13. Khan SQ, Moheet IA, Farooq I, Farooqi FA, ArRejaie AS, Al Abbad MA, et al. Prevalence of dental fluorosis in school going children of Dammam, Saudi Arabia. J Dent Allied Sci. 2015;4:69-72.
14. Bhalla A, Malik S, Sharma S. Prevalence of. dental fluorosis among school children residing in Kanpur City, Uttar Pradesh, India. Eur J Gen Dent. 2015;4:59-63.

15. Chaudhry M, Prabhakar I, Gupta B, Anand R, Sehrawat P, Thakar SS. Prevalence of Dental Fluorosis Among Adolescents in Schools of Greater Noida, Uttar Pradesh. $J$ Indian Assoc Public Health Dent. 2017;15:36-41.

16. Reddy KS, Puppala R, Kethineni B, Reddy H, Reddy A, Kalyan VS. Prevalence of dental fluorosis among 6-12-yearold school children of Mahabubnagar district, Telangana State, India -A cross-sectional study. J Indian Assoc Public Health Dent. 2017;15:42-7.

17. Patel HR, Shah H, Kalyan P, Krishnan CGA, Thanveer K, Chaudhary N, et al. Prevalence of dental fluorosis among 12 year old school going children of Piparia Village, Vadodara: A cross- sectional survey. J Res Adv Dent. 2017;6:2s:71-4.

18. Chauhan D, Chauhan T, Sachdev V, Kirtaniya BC. A study of prevalence and severity of dental fluorosis among school children in a Northern hilly state of India. SRM J Res Dent Sci. 2012;3:170-4

19. Sarvaiya BU, Bhayya D, Arora R, Mehta DN. Prevalence of dental fluorosis in relation with different fluoride levels in drinking water among school going children in Sarada tehsil of Udaipur district, Rajasthan. J Indian Soc Pedod Prev Dent. 2012;30:317-22.

20. Verma A, Shetty BK, Guddattu V, Chourasia MK, Pundir P. High prevalence of Dental Fluorosis among adolescents is a growing concern: a school based cross - sectional study from Southern India. Environ Health Prev Med. 2017;22:17.

How to cite this article: Nimbannavar SM, Yuvaraj BY, Mane V, Anilkumar L, Holyachi S, Chetana KV. Prevalence of dental fluorosis and its determinants among primary school children in Koppal district, Karnataka: A cross-sectional study. Indian J Forensic Community Med. 2020;7(1):7-10. 